\title{
Endoscopic Submucosal Dissection for Colitis-Associated Dysplasia
}

\author{
Dong-Hoon Yang ${ }^{1}$ and Imelda Rey ${ }^{2}$ \\ ${ }^{1}$ Department of Gastroenterology, Asan Medical Center, University of Ulsan College of Medicine, Seoul, Korea, ${ }^{2}$ Division of \\ Gastroenterohepatology, Department of Internal Medicine, University of Sumatera Utara, Adam Malik General Hospital, Medan, Indonesia
}

Dysplasia is a precancerous lesion of colorectal cancer in patients with long-standing inflammatory bowel diseases (IBDs), such as ulcerative colitis and Crohn's disease. Recent guidelines suggest endoscopic resection as a key modality for the treatment of endoscopically resectable dysplasia in patients with colitis. Endoscopic submucosal dissection (ESD) has been suggested as one of the therapeutic options for dysplasia that is potentially resectable but not suitable for the conventional endoscopic mucosal resection technique. Several recent studies supported the feasibility of ESD for the treatment of colitis-associated dysplasia in terms of the en $b l o c$ and complete resection rates and the risk of procedure-related complications. However, these studies were performed exclusively in expert centers. Moreover, the local and metachronous recurrence rates were relatively high, and long-term outcome data are still lacking. Endoscopists should be highly skilled in colorectal ESD and have an intensive understanding of not only the lesions but also the conditions of patients with IBDs. Therefore, the decision to perform ESD for colitis-associated dysplasia should be made scrupulously after careful discussion with patients, in collaboration with a multidisciplinary IBD team including physicians, surgeons, and pathologists specialized in IBDs. Clin Endosc 2019;52:120-128

Key Words: Inflammatory bowel disease; Ulcerative colitis; Dysplasia; Endoscopic submucosal dissection

\section{INTRODUCTION}

The risk of colorectal cancer (CRC) is increased in patients with inflammatory bowel diseases (IBDs) compared with that in the general population, ${ }^{1-3}$ and dysplasia is considered as a precancerous lesion of CRC in long-standing ulcerative colitis (UC) or Crohn's disease. ${ }^{4}$ Traditionally, total proctocolectomy (TPC) has been regarded as a standard treatment for UC-associated dysplasia. ${ }^{4}$ However, since early studies on the feasibility of polypectomy for dysplasia, ${ }^{5,6}$ subsequent studies have supported the therapeutic role of colonoscopic polypectomy for polypoid dysplasia in patients with colitis. The pooled

Received: February 18, 2019 Revised: March 16, 2019

Accepted: March 17, 2019

Correspondence: Dong-Hoon Yang

Department of Gastroenterology, Asan Medical Center, University of Ulsan College of Medicine, 88 Olympic-ro 43-gil, Songpa-gu, Seoul 05505, Korea Tel: +82-2-3010-5809, Fax: +82-2-3010-6517, E-mail: dhyang@amc.seoul.kr ORCID: https://orcid.org/0000-0001-7756-2704

(c) This is an Open Access article distributed under the terms of the Creative Commons Attribution Non-Commercial License (http://creativecommons.org/ licenses/by-nc/3.0) which permits unrestricted non-commercial use, distribution, and reproduction in any medium, provided the original work is properly cited. incidence of CRC after endoscopic resection of polypoid dysplasia is 5.3 cases per 1,000 patient-years in patients with colitis, ${ }^{7}$ and the incidence of interval CRC was 2.5 cases per 1,000 patient-years in a recent large surveillance study on patients with colitis. ${ }^{8}$ Therefore, recent guidelines suggest endoscopic resection as a key modality for the treatment of visible and endoscopically resectable dysplasia in these patients. ${ }^{9-11}$ Endoscopic submucosal dissection (ESD) has been proposed as a resection technique for non-polypoid dysplasia, ${ }^{11,12}$ especially when conventional endoscopic mucosal resection (EMR) is not suitable for en bloc resection. However, only a small number of studies reported the feasibility of ESD for colitis-associated dysplasia to date. Herein, we review the feasibility and limitation of ESD for colitis-associated dysplasia.

\section{ENDOSCOPIC DESCRIPTION AND CLASSIFICATION FOR DYSPLASIA}

The old terms to describe the gross appearance of colitis-associated dysplasia were notoriously confusing. The term "dysplasia-associated lesion or mass (DALM)" had been coined 
to describe endoscopically visible dysplasia showing heterogenous appearances, such as single polypoid mass, plaquelike lesions, and multiple polyps, in $19811^{13}$ "Flat dysplasia" had been frequently used to describe invisible dysplasia detected by random biopsy in the past. ${ }^{14}$ However, as more dysplasias have become visible and characterizable under endoscopy, the need for new and less-confusing classification systems has increased. The recent international consensus statement of the Surveillance for Colorectal Endoscopic Neoplasia Detection and Management in Inflammatory Bowel Disease Patients (SCENIC) suggested a new classification system for dysplasia identified on surveillance colonoscopy. ${ }^{10,11}$ First, dysplasia should be divided into visible and invisible dysplasias. Therefore, flat dysplasia is no longer categorized as invisible dysplasia in the SCENIC classification. Second, the other imprecise terms, including DALM, adenoma-lesion or mass, and non-adenoma-like dysplasia, were abandoned. Instead, the Paris classification for sporadic colorectal neoplasia (CRN) was adopted to describe visible dysplasia. Third, two general descriptors for dysplasia, i.e., presence of ulcerations and distinctness of borders, should be considered. Presence of surface ulcerations and indistinct borders are currently suggested as features of endoscopically unresectable dysplasia. ${ }^{11}$ Compared with previous descriptions for dysplasia, this new classification can be a more uniformed communication tool among endoscopists.

\section{ENDOSCOPIC FEATURES POTENTIALLY PREDICTIVE OF DEEP SUBMUCOSAL INVASION IN DYSPLASIA}

Because of the increased risk of lymph node metastasis, deep submucosal invasive CRC should be treated surgically instead of performing endoscopic resection if it can be predicted precisely. ${ }^{15}$ However, the predictive factors of deep submucosal invasion are not well established in patients with long-standing colitis.

In sporadic CRN, type Vn Kudo pit pattern and invasive narrow band image (NBI) patterns, such as Sano type IIIB or Japan NBI expert team type 3, are closely associated with deep submucosal invasion. ${ }^{16-19}$ According to a recent meta-analysis on deep submucosal invasion prediction in sporadic $\mathrm{CRN}$, the pooled estimates of sensitivity were $77 \%$ for NBI and $81 \%$ for magnifying chromoendoscopy, while those of specificity were $98 \%$ for NBI and $95 \%$ for magnifying chromoendoscopy. ${ }^{20}$ Neoplastic pit patterns are deemed to predict dysplasia or neoplasia less accurately in patients with IBDs than in those without. The diagnostic accuracy of neoplastic pit patterns in predicting sporadic CRN reached $98 \%$ in a study. ${ }^{21} \mathrm{Neo}-$ plastic pit patterns predicted neoplasia, with sensitivity of $89 \%$ and specificity of $86 \%$, in a meta-analysis that included studies based mostly on patients without colitis. ${ }^{22}$ Conversely, neoplastic pit patterns could discriminate dysplasia from non-dysplasia, with a relatively low accuracy $(62 \%-73 \%),{ }^{23-25}$ in patients with colitis, except in an early study that reported excellent diagnostic performance of neoplastic pit patterns (sensitivity of $94 \%$, specificity of $93 \%$, and accuracy of $92 \%$ for predicting dysplasia). ${ }^{26}$ Discrimination between carcinoma or high-grade dysplasia and low-grade dysplasia using NBI and magnifying chromoendoscopy is also challenging. A recent study reported sensitivity of $72.2 \%$, specificity of $85.7 \%$, and accuracy of $76 \%$ for differentiating carcinoma or high-grade dysplasia from low-grade dysplasia. ${ }^{27}$ Given these data, invasive pit or NBI patterns may predict deep submucosal invasion less accurately in colitis-associated dysplasia/CRC than in sporadic CRN, although no comparative study is available yet.

Depression, presence of overlying ulceration, and failure to lift with attempted submucosal injection are suggested as gross features of submucosal invasion in dysplasia. ${ }^{11}$ Of these findings, failure to lift with attempted submucosal injection may be often different from the positive non-lifting sign typically observed in deep submucosal invasive CRC in patients without colitis. A classic positive non-lifting sign is originally defined as non-lifting of the lesion with elevated surrounding mucosa after submucosal injection. ${ }^{28}$ However, as the background of the lesion often has extensive scar changes, especially in patients with UC, not only the lesion itself, but also the surrounding area may not be lifted (diffuse non-lifting sign; Fig. 1). The diagnostic performance of these three gross features for predicting deep submucosal invasion is still unknown in patients with IBDs and thus needs to be investigated.

\section{TECHNICAL CONSIDERATIONS FOR ESD OF COLITIS-ASSOCIATED DYSPLASIA}

The techniques and equipment for ESD for sporadic CRNs have been described in many publications, ${ }^{29-31}$ and the basic steps of ESD for sporadic CRNs can also be applied for UC-associated dysplasia (Fig. 2). High-definition endoscope systems and a transparent cap attached to the distal end of the scope are necessary for ESD. Endoknives and electrosurgical units are also essential. Careful observation of the target lesion should be the first step of ESD. Dye chromoendoscopy and/or image-enhanced endoscopy is useful for delineating the margins and characterizing the lesion surfaces. Circumferential diathermic marks before submucosal injection are not generally required during ESD for sporadic $\mathrm{CRN}^{29}$ because the 
margins of sporadic CRN are endoscopically distinguishable from the surrounding non-neoplastic mucosa. However, the surrounding mucosa of UC-associated dysplasia frequently shows chronic inflammatory or scar changes, ${ }^{32,33}$ which the operator may confuse with true dysplasia during a prolonged procedure. Therefore, we recommend making diathermic marks around the margins of dysplasia before injecting a submucosal solution, even if the borders are distinct (Fig. 3). A viscous solution, such as sodium hyaluronate solution, is preferred for submucosal injection, as it can provide a prolonged submucosal cushion. ${ }^{34}$ Using an endoknife, a partial mucosal incision should be created at approximately $3-5 \mathrm{~mm}$ apart from the delineated margins. Circumferential mucosal incision created at once is not recommended for colorectal ESD because the submucosal solution will leak out easily. Trimming beneath the initial mucosal incision can expose the submucosal layer, and submucosal dissection should be followed. Once the submucosal layer is dissected enough to form a flap or a pocket, the operator can gently press and stretch the submucosal layer using the scope with a transparent cap. With this maneuver, the interface between the proper muscle and submucosal layers is visible via the transparent submucosal layer while submucosal dissection is performed.

\section{HISTOLOGICAL ASSESSMENT OF RESECTED SPECIMENS}

The histological features of colitis-associated dysplasia, which are different from those of sporadic colorectal adenoma, can be summarized as follows: unclear delineation between neoplastic and non-neoplastic areas; variety in config-
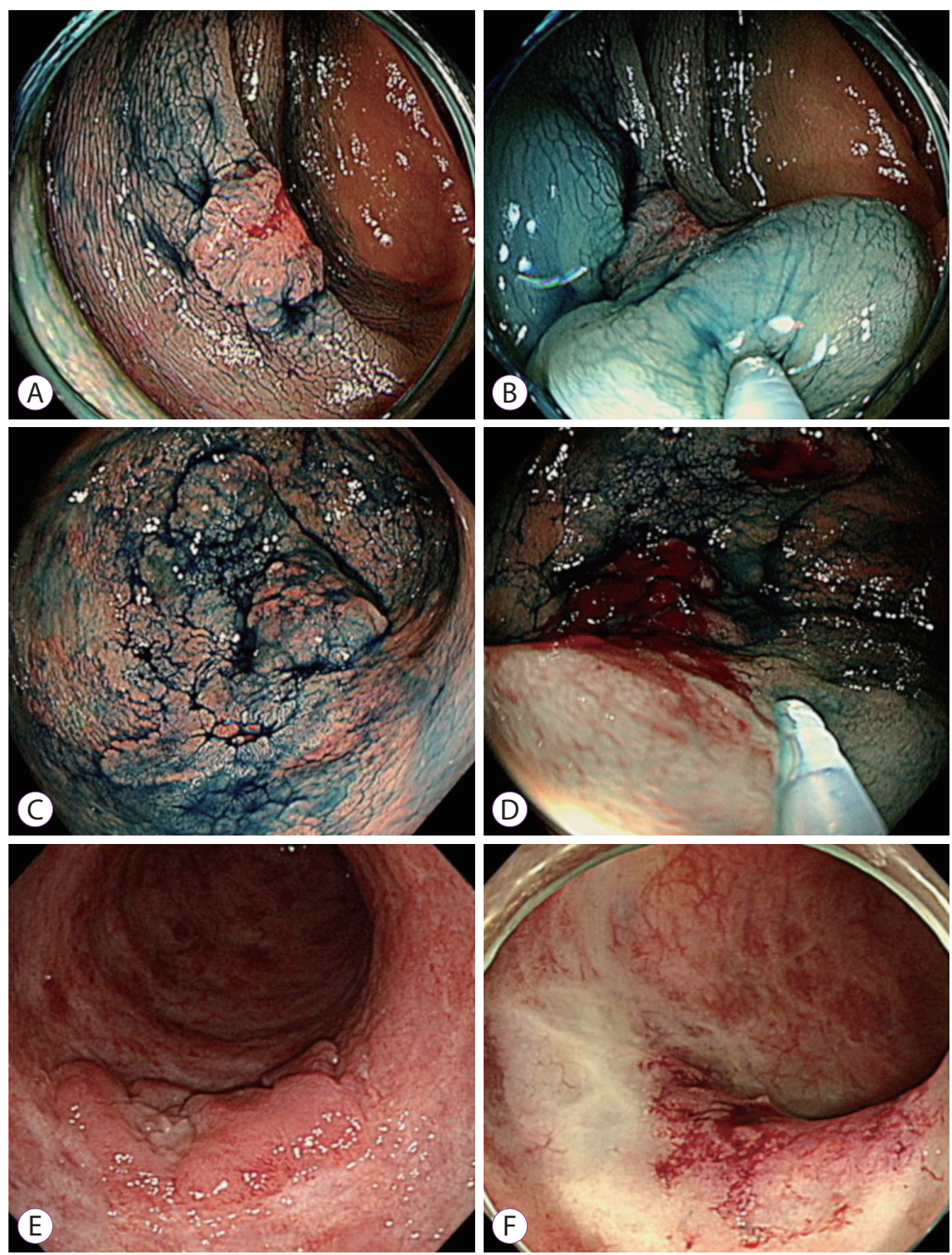

Fig. 1. (A, B) A classic non-lifting sign was observed in sporadic deep submucosal invasive cancer. The lesion was not lifted; however, the surrounding mucosa was elevated after submucosal injection. The final histology of this lesion was SM3 adenocarcinoma. (C, D) A classic non-lifting sign was observed in colitis-associated dysplasia. The dysplasia itself was not lifted; however, the surrounding mucosa was lifted after submucosal injection. Its colectomy specimen revealed an adenocarcinoma invading the proper muscle (T2 stage). ( $E, F)$ A diffuse non-lifting sign was observed in colitis-associated dysplasia located on the extensive scar changes. Neither the dysplasia nor the surrounding mucosa was lifted after submucosal injection. The final histology of this lesion was lowgrade dysplasia. 

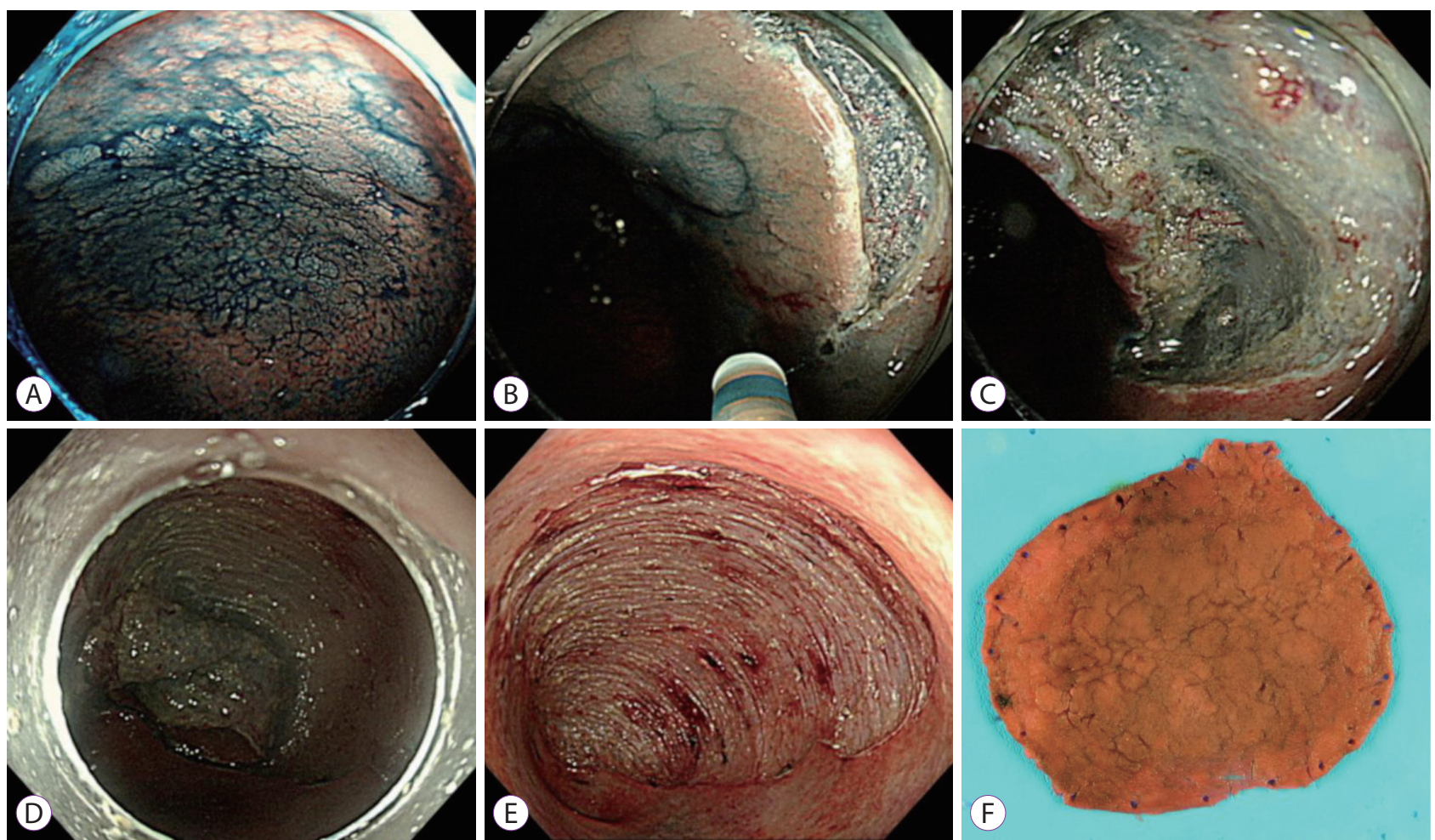

Fig. 2. Representative example of endoscopic submucosal dissection for colitis-associated dysplasia. (A) Large, non-ulcerated Paris type O-lla dysplasia with a distinct border in the rectum. (B) Mucosal incision was performed after submucosal injection. (C) Mild but diffuse submucosal fibrosis and submucosal fat deposition. (D-F) The colonoscope was changed into a gastroscope to expose the submucosal layer more effectively, and en bloc resection was achieved. The final histology revealed low-grade dysplasia ( $42 \times 40 \mathrm{~mm}$ in size, with clear lateral and vertical margins).
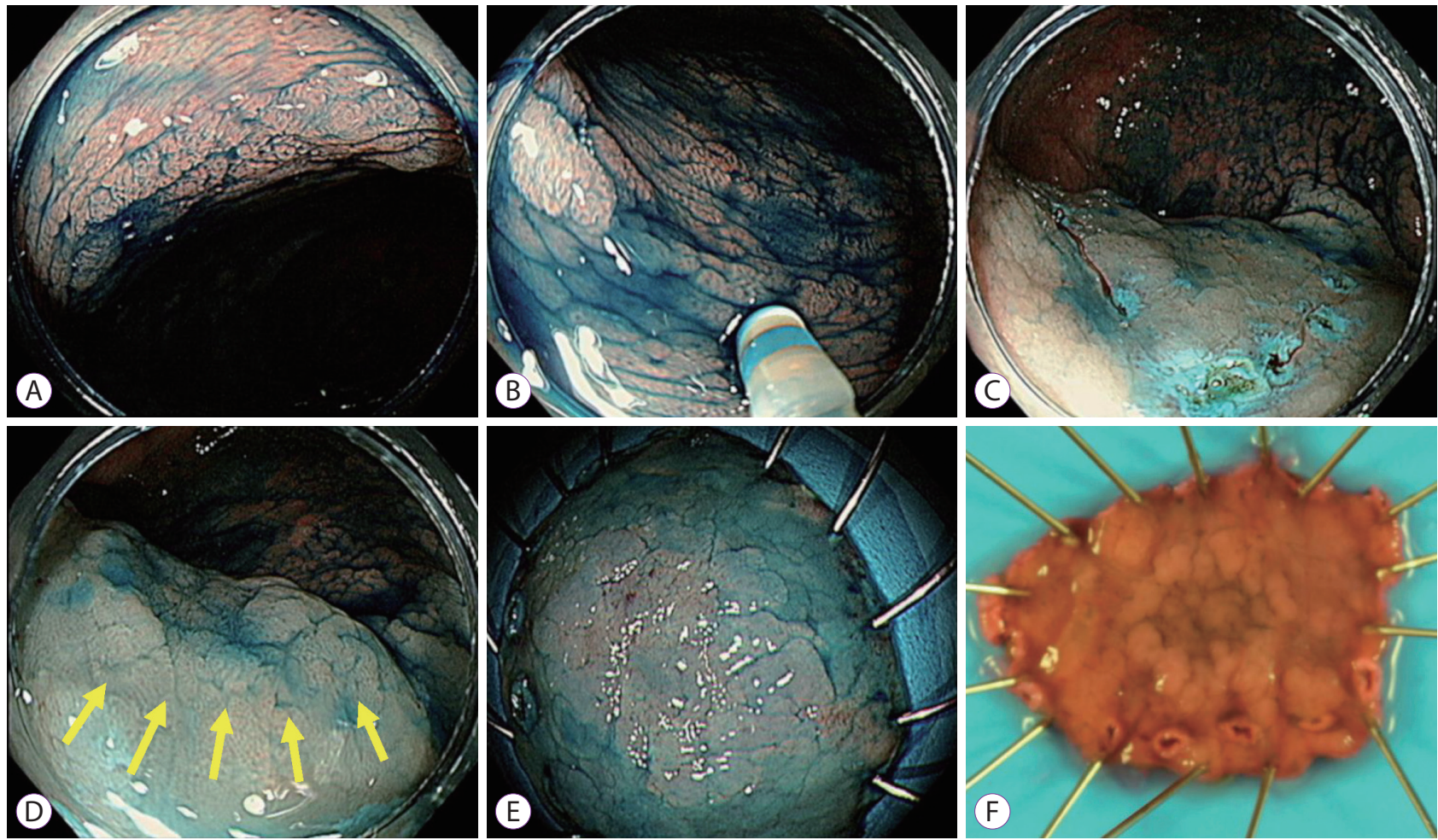

Fig. 3. (A, B) Diathermic marks were made; the border of the dysplasia was clearly distinguishable under dye chromoendoscopy. (C, D) After submucosal injection, the border of the lesion became less distinguishable. (E, F) Endoscopic submucosal dissection was performed along the diathermic marks, and en bloc complete resection was possible. The final histology was low-grade dysplasia ( $15 \times 10 \mathrm{~mm}$ in size, with clear lateral and vertical margins). 
uration, size, and diameter of the neoplastic glands; increased infiltration of mononuclear inflammatory cells at the laminar propria; mixtures of the dysplastic and non-dysplastic glands at the lesion surface; and neoplastic proliferation from the base of the gland to the surface. ${ }^{35,36}$ These features themselves can confuse the pathologists with true dysplasia and reactive changes and are not actually universally observed in dysplasias. Consequently, the histological diagnosis of dysplasia occasionally shows discrepancies across pathologists, especially between unspecialized and specialized pathologists. ${ }^{37-39}$ Current guidelines recommend that the diagnosis of dysplasia should be confirmed by a gastrointestinal (GI) specialist pathologist. ${ }^{9,10}$

Similar to the studies on ESD for sporadic CRNs, the currently available studies on ESD for UC-associated dysplasia defined "complete (R0) resection" as en bloc resection with tumor-negative lateral and vertical margins at histology and "curative resection" as R0 resection with superficial $(<1,000$ $\mathrm{mm}$ from the muscularis mucosa) submucosal invasion, no lymphovascular involvement, and good cell differentiation. ${ }^{27,32,33,40}$ Therefore, in addition to the grading for dysplasia, both completeness and curativeness should be assessed by a GI specialist pathologist who has expertise in interpreting dysplasia in patients with IBDs.

Conversely, whether biopsies should be obtained from the adjacent mucosa after removing dysplasias is not established yet. Recent studies mostly based on polypoid dysplasia showed that the yield of peri-lesional biopsies ranged from $0.3 \%$ to $5 \%,{ }^{41-43}$ and one of them revealed that the diagnostic yield of peri-lesional biopsies from the mucosa not suspicious of dysplasia was $0 \%{ }^{43}$ Therefore, peri-lesional biopsies after endoscopic resection of dysplasia may not be mandatory, especially if the peri-lesional mucosa appears normal under endoscopy. However, limited knowledge is currently known regarding the prevalence of invisible or endoscopically unsus- pected dysplasia around non-polypoid dysplasia. Therefore, we recommend performing four-quadrant biopsies routinely from the margins of the postprocedural ulceration after ESD, until the yield of peri-lesional biopsies for non-polypoid dysplasias can be determined.

\section{OUTCOMES OF ESD FOR COLITIS- ASSOCIATED DYSPLASIA}

Although ESD has been suggested as a resection technique for non-polypoid dysplasia, ${ }^{11,12}$ its outcomes for non-polypoid dysplasia in patients with colitis were reported in several recent studies. The reported outcomes related to ESD for colitis-associated dysplasia or early CRC include the en bloc and $\mathrm{R} 0$ resection rates, curative resection rate, adverse events, local recurrence, and metachronous recurrence (Table 1).

\section{$E n$ bloc and complete resection rates}

The en bloc and R0 resection rates of ESD for UC-associated dysplasia were reported in several recent studies. Iacopini et al. first reported their experience in ESD for 10 UC-associated dysplasias in nine Italian or Japanese patients. ${ }^{32}$ The median size of the lesions was $30 \mathrm{~mm}$ (range, $20-50 \mathrm{~mm}$ ), and the en bloc and R0 resection rates were $80 \%$ and $80 \%$, respectively. ${ }^{32}$ After this earliest case series, two studies reported the outcomes of ESD for UC-associated dysplasia or early CRC. Suzuki et al. reported the outcome of ESD procedures for 32 lesions (median size $=33 \mathrm{~mm}$ ) in British or Japanese patients with UC, and their en bloc and R0 resection rates were 97\% and $72 \%$, respectively. ${ }^{40}$ Around the same time, Kinoshita et al. reported the outcomes of ESD performed in two Japanese referral centers, and the en bloc and R0 resection rates for 25 lesions (mean size $=21.6 \mathrm{~mm}$ ) were $100 \%$ and $76 \%$, respectively. ${ }^{27}$ According to a very recent study conducted in a single

Table 1. Characteristics of the Lesions and Procedure-Related Outcomes of the Studies for the Endoscopic Submucosal Dissection of the Dysplasia or Early Colorectal Cancer in the Patients having Ulcerative Colitis

\begin{tabular}{|c|c|c|c|c|c|c|c|c|}
\hline Study & $\begin{array}{l}\text { Number } \\
\text { of cases }\end{array}$ & $\begin{array}{l}\text { Size of the lesions, } \\
\text { mm, median (range) } \\
\text { or mean } \pm \text { SD }\end{array}$ & $\begin{array}{l}\text { Submuco- } \\
\text { sal fibrosis }\end{array}$ & $\begin{array}{c}\text { ESD time, minutes, } \\
\text { median (range) or } \\
\text { mean } \pm \text { SD }\end{array}$ & $\begin{array}{c}\text { En bloc } \\
\text { resection }\end{array}$ & $\begin{array}{l}\text { R0 resec- } \\
\text { tion }\end{array}$ & $\begin{array}{l}\text { Delayed } \\
\text { bleeding }\end{array}$ & $\begin{array}{l}\text { Perfora- } \\
\text { tion }\end{array}$ \\
\hline $\begin{array}{l}\text { Iacopini et al. } \\
(2015)^{32}\end{array}$ & 10 & $15(10-20)$ & $90 \%$ & $63(45-130)$ & $80 \%$ & $80 \%$ & $\begin{array}{c}10 \% \\
(1 / 10)\end{array}$ & 0 \\
\hline $\begin{array}{l}\text { Suzuki et al. } \\
(2017)^{40}\end{array}$ & 32 & $33(12-73)$ & $97 \%$ & $87(6-290)$ & $97 \%$ & $79 \%$ & $\begin{array}{c}3.1 \% \\
(1 / 32)\end{array}$ & 0 \\
\hline $\begin{array}{l}\text { Kinoshita et al. } \\
(2018)^{27}\end{array}$ & 25 & $21.6 \pm 12.8$ & $100 \%$ & $71.7 \pm 53.7$ & $100 \%$ & $76 \%$ & 0 & $4 \%(1 / 25)$ \\
\hline Yang et al. (2019) $)^{33}$ & 15 & $23(12-48)$ & $66.7 \%$ & $61(12-160)$ & $93.3 \%$ & $80 \%$ & 0 & 0 \\
\hline
\end{tabular}

ESD, endoscopic submucosal dissection; SD, standard deviation. 
Korean referral center, the en bloc and R0 resection rates for 15 UC-associated dysplasias (median size $=23 \mathrm{~mm}$ ) were $93.3 \%$ and $80 \%$, respectively. ${ }^{33}$ These results are comparable with the en bloc resection rates of $89 \%-92 \%$ and complete resection rates of $76 \%-83 \%$ in colorectal ESDs exclusive for sporadic CRNs. ${ }^{446}$ The curative resection rates of ESD for UC-associated dysplasias ranged from $70 \%$ to $80 \%,{ }^{27,32,33}$ which are also comparable with the curative resection rate of ESD for sporadic CRNs (80.9\%; 95\% confidence interval [CI], 76.0\%$85.0 \%)^{46}$

\section{Submucosal fibrosis and dissection speed}

UC-associated dysplasias may have submucosal fibrosis more frequently than sporadic CRNs, and the incidence of submucosal fibrosis ranged from $66.7 \%$ to $100 \%$ in previous studies on ESD for dysplasias. ${ }^{32,33,40}$ The presence of submucosal fibrosis may slow the dissection speed down, and the median dissection speed of ESD was $0.065 \mathrm{~cm}^{2} / \mathrm{min}$ in a study reporting a $90 \%$ frequency of submucosal fibrosis ${ }^{32}$ and $0.083 \mathrm{~cm}^{2} / \mathrm{min}$ in another study reporting a $97 \%$ frequency of submucosal fibrosis. ${ }^{40}$ Their dissection speeds seem relatively slower than that of non-granular-type laterally spreading tumor (LST-NG) cases in a previous study on ESD for sporadic CRNs $\left(0.15 \mathrm{~cm}^{2} / \mathrm{min}\right)$. However, in a recent Korean study, which reported an incidence of submucosal fibrosis of $66.7 \%$, the dissection speed was $0.13 \mathrm{~cm}^{2} / \mathrm{min}$, which is comparable with the dissection speed of ESDs for sporadic LST-NGs. ${ }^{33}$ The median procedure time of ESD for dysplasias ranged from 61 to 87 minutes in three studies. ${ }^{32,33,40}$ The mean ( \pm standard deviation) procedure time of ESD in another study was $71.7 \pm 53.7$ minutes. $^{27}$

\section{Adverse events}

Bleeding and perforation are major complications related to colorectal ESDs, and their incidence during ESD for sporadic
CRNs has been reported as 2.7\% (95\% CI, 2.2\%-3.2\%) and 5.2\% (95\% CI, 4.4\%-6.1\%), respectively, in a recent meta-analysis. ${ }^{46}$ Among studies on ESD for UC-associated dysplasias, delayed bleeding occurred in two studies, and its incidence was 10\% $(1 / 10)$ in the first study ${ }^{32}$ and $3.1 \%(1 / 32)$ in the second study. ${ }^{40}$ Conversely, only one study reported a case of perforation ( $4 \%$, $1 / 25)^{27}$

\section{Outcome of surveillance after ESD}

The proportion of the patients who underwent colectomy after ESD ranged from $6.7 \%$ to $20 \%$, and non-curative resection was the main reason for surgery (Table 2). ${ }^{27,32,33,40}$ The earliest case series reported two cases of local recurrence after ESD for nine dysplasias during a median follow-up duration of 24 months; both of them occurred in the piecemeal resection cases. ${ }^{32}$ Metachronous dysplasias developed in three of eight patients (37.5\%) during the same follow-up period. ${ }^{32}$ Suzuki et al. reported local and metachronous recurrence rates of $3.8 \%$ and $11.5 \%$, respectively, during a median follow-up duration of 33 months. ${ }^{40}$ Kinoshita et al. reported a local recurrence rate of $0 \%$ and a metachronous recurrence rate of $4 \%$ during a median follow-up duration of 21 months. ${ }^{27}$ However, a single Korean referral center study on ESD for dysplasia with a median follow-up duration of 24.7 months reported that both the local and metachronous recurrence rates were $14.3 \%{ }^{33} \mathrm{~A}$ heterogeneous level of risk for dysplasia or colitic cancer among patients is potentially associated with the wide variation in the metachronous recurrence rates during post-ESD surveillance. Nonetheless, given that the pooled local recurrence rate was 2.0\% (95\% CI, 1.3\%-3.0\%) after ESD for sporadic CRNs in a meta-analysis, ${ }^{46}$ local recurrence after ESD for UC-associated dysplasias should be regarded more frequent than that after ESD for sporadic CRNs. Additional studies should be conducted to reveal the long-term post-ESD outcomes, such as the recurrence rate and the incidence of post-ESD CRC.

Table 2. The Therapeutic Outcomes of Endoscopic Submucosal Dissection for the Colitis-Associated Dysplasia

\begin{tabular}{|c|c|c|c|c|}
\hline Study & Rate and reason of colectomy after ESD & Local recurrence & $\begin{array}{l}\text { Metachronous } \\
\text { recurrence }\end{array}$ & $\begin{array}{l}\text { Follow-up, mo, } \\
\text { median (range) }\end{array}$ \\
\hline $\begin{array}{l}\text { Iacopini et al. } \\
(2015)^{32}\end{array}$ & $\begin{array}{l}10 \%(1 / 10) \\
\text { T1 cancer with vascular invasion }(n=1)\end{array}$ & $22.2 \%(2 / 9)$ & $37.5 \%(3 / 8)$ & $24(6-72)$ \\
\hline $\begin{array}{l}\text { Suzuki et al. } \\
\qquad(2017)^{40}\end{array}$ & $\begin{array}{l}12.5 \%(4 / 32) \\
\text { T1 cancer }(n=2) \\
\text { Invisible dysplasia }(n=1) \\
\text { Patient's preference for treating visible dysplasia }(n=1)\end{array}$ & $3.8 \%(1 / 26)$ & $11.5 \%(3 / 26)$ & $33(6-76)$ \\
\hline $\begin{array}{l}\text { Kinoshita et al. } \\
(2018)^{27}\end{array}$ & $\begin{array}{l}20 \%(5 / 25) \\
\text { T1 cancer with non-curative resection }(n=5)\end{array}$ & 0 & $5 \%(1 / 20)$ & $21(8-80)$ \\
\hline $\begin{array}{l}\text { Yang et al. } \\
(2019)^{33}\end{array}$ & $\begin{array}{l}6.7 \%(1 / 15) \\
\text { Missed synchronous T1 cancer detected during ESD }(n=1)\end{array}$ & $14.3 \%(2 / 14)$ & $14.3 \%(2 / 14)$ & $24.7(5.2-64.8)$ \\
\hline
\end{tabular}

ESD, endoscopic submucosal dissection. 


\section{COLECTOMY FOR COLITIS-ASSOCIATED DYSPLASIA}

Colectomy is indicated for the treatment of endoscopically unresectable dysplasias in patients with UC. ${ }^{9,11}$ However, according to survey-based studies, a considerable proportion of patients with IBDs would refuse colectomy for the treatment of dysplasia, ${ }^{47-49}$ and the fear of permanent ostomy or complications was the main reason for refusal of surgical treatment. ${ }^{49}$

TPC with ileal pouch-anal anastomosis (IPAA) has become a surgical procedure of choice for patients with UC, as the postoperative clinical and functional outcomes were stable during long-term follow-ups. ${ }^{50,51}$ However, the mean daytime bowel frequency ranged from 5.7 at 1 year to 6.4 at 20 years. $^{50}$ Therefore, patients with UC in remission may not agree with the physician's recommendation for surgery if they have dysplasia, not cancer. In a Korean multicenter retrospective study, ${ }^{52} 415$ patients with UC underwent colon surgery, and most of them (92.2\%) underwent TPC. Medical intractability of UC ( $n=270,65.1 \%)$ was the most common indication of surgery, followed by dysplasia or malignancy ( $n=52,12.5 \%$ ). The overall postoperative complication rate was $34.7 \%$. Ileus ( $n=21)$, bleeding $(n=16)$, and anastomotic leakage $(n=15)$ were common early postoperative complications. Pouchitis $(n=48)$ was the most common late complication. In another largescale ( $n=3,707)$ study including 2,953 patients with UC and 150 patients with Crohn's disease, the early and late complication rates in TPC with IPAA were $33.5 \%$ and $29.1 \%$, respectively. ${ }^{53}$ The authors also reported a perioperative mortality rate of $0.1 \%$.

Therefore, the decision to undergo colectomy for dysplasia should be highly individualized, and the patients' clinical status, life expectancy, and preferences must be considered. ${ }^{54}$ The final decision should be balanced between these factors and the risk of CRC.

\section{FEASIBILITY AND APPROPRIATE CONDITIONS OF ESD FOR COLITIS- ASSOCIATED DYSPLASIA}

The procedure-related outcome measures of ESD for colitis-associated dysplasias, such as the en bloc and R0 resection rates and incidence of complications, are comparable with those of ESD for sporadic CRNs. However, such data are based on small studies reported by groups with a high level of expertise. . $732,33,40$ Moreover, the local and metachronous recurrence rates are relatively high, and no long-term outcome data are available yet. Nonetheless, given the functional outcome and risk of complications related to colectomy, ESD can be considered feasible for dysplasia that cannot be removed using the conventional EMR techniques.

The most appropriate conditions for attempting ESD for colitis-associated dysplasia can be suggested as follows (Table 3). First, the peri-lesional mucosa should be in remission endoscopically. Second, the patients' colitis itself should be medically tractable. Third, any of the endoscopic findings indicating possible invasive cancer should be absent, although the diagnostic performance of invasive pit or vascular patterns, surface ulcerations, and the non-lifting sign has not been determined yet. Fourth, an expert endoscopist highly skilled in both colorectal ESD and surveillance colonoscopy for patients with colitis should assess the lesion and perform ESD. The endoscopists in the currently available studies already had expertise in colorectal ESD before performing ESD for colitis-associated dysplasia. ${ }^{27,32,33,40}$ However, the qualification needed

Table 3. Suggestion for the Required Conditions for Attempting Endoscopic Submucosal Dissection for Colitis-Associated Dysplasia

\begin{tabular}{ll}
\hline Colitis & Suggested requirements \\
& Peri-lesional mucosa should be in endoscopic remission (Mayo subscore 0-1 or UCEIS 0-2) \\
& The patient should be at least in clinical remission and preferably in endoscopic and histologic remission \\
Dysplasia & Should satisfy all of the following conditions \\
& Distinct border \\
& No surface ulceration \\
& Absence of non-lifting sign which precludes any further submucosal dissection \\
& Absence of endoscopic features suggesting invasive cancer \\
Endoscopist & Should be highly-skilled in colorectal ESD \\
& Should have expertise in the surveillance colonoscopy for effective monitoring after ESD \\
Pathologist & Should have expertise in the histologic interpretation of the dysplasia in the colitic patients \\
IBD physician & Should be available to provide the proper management and surveillance after curative ESD \\
IBD surgeon & Should be available to provide the proper management after non-curative ESD \\
\hline
\end{tabular}

ESD, endoscopic submucosal dissection; IBD, inflammatory bowel disease; UCEIS, ulcerative colitis endoscopic index of severity. 
for performing ESD of colitis-associated dysplasia among endoscopists is not currently available. A recent Korean study reported that the first ESD for colitis-associated dysplasia had been attempted after approximately 200 cases of ESD experiences. ${ }^{33}$ Fifth, a GI pathologist specialized in interpreting the histology of dysplasia should be available. Finally, both an IBD physician and an IBD surgeon should be available to provide proper management after curative or non-curative ESDs, respectively. Therefore, we strongly suggest that ESD for colitis-associated dysplasia be performed by an ESD expert endoscopist in a center with a well-organized IBD team.

\section{CONCLUSIONS}

ESD has been suggested as one of the therapeutic options for endoscopically resectable dysplasia in patients with colitis. Recent studies performed by expert centers support the feasibility of ESD for the treatment of colitis-associated dysplasia in terms of the en bloc and R0 resection rates and the risk of procedure-related complications. The relatively high incidence of colectomy-related complications justifies selecting ESD as a primary treatment for endoscopically resectable dysplasia that cannot be effectively treated using the conventional EMR technique. However, the local and metachronous recurrence rates after ESD for colitis-associated dysplasia are relatively high, and long-term therapeutic outcome data are still lacking. In addition, the lesion and patient characteristics suitable for performing ESD are not well established in colitis-associated dysplasia. Therefore, the therapeutic decision for colitis-associated dysplasia, which potentially needs ESD, should be made after individualized and multidisciplinary approach in close collaboration with a multidisciplinary IBD team. The lesion characteristics, patients' general medical conditions and preferences, and status of colitis must be taken into consideration. After curative ESD, meticulous colonoscopic surveillance is mandatory to monitor for local and metachronous recurrences of dysplasia. Further studies should be conducted to establish the long-term therapeutic outcomes of ESD, such as the incidence of post-ESD CRC and the risk of colectomy after ESD.

\section{Conflicts of Interest}

The authors have no financial conflicts of interest.

\section{REFERENCES}

1. Jess T, Rungoe C, Peyrin-Biroulet L. Risk of colorectal cancer in patients with ulcerative colitis: a meta-analysis of population-based cohort stud- ies. Clin Gastroenterol Hepatol 2012;10:639-645.

2. Colman RJ, Rubin DT. Histological inflammation increases the risk of colorectal neoplasia in ulcerative colitis: a systematic review. Intest Res 2016;14:202-210.

3. Zhiqin W, Palaniappan S, Raja Ali RA. Inflammatory bowel disease-related colorectal cancer in the Asia-Pacific region: past, present, and future. Intest Res 2014;12:194-204.

4. Velayos F, Kathpalia P, Finlayson E. Changing paradigms in detection of dysplasia and management of patients with inflammatory bowel disease: is colectomy still necessary? Gastroenterology 2017;152:440-450.el.

5. Rubin PH, Friedman S, Harpaz N, et al. Colonoscopic polypectomy in chronic colitis: conservative management after endoscopic resection of dysplastic polyps. Gastroenterology 1999;117:1295-1300.

6. Engelsgjerd M, Farraye FA, Odze RD. Polypectomy may be adequate treatment for adenoma-like dysplastic lesions in chronic ulcerative colitis. Gastroenterology 1999;117:1288-1294; discussion 1488-1491.

7. Wanders LK, Dekker E, Pullens B, Bassett P, Travis SP, East JE. Cancer risk after resection of polypoid dysplasia in patients with longstanding ulcerative colitis: a meta-analysis. Clin Gastroenterol Hepatol 2014;12:756-764.

8. Mooiweer E, van der Meulen-de Jong AE, Ponsioen CY, et al. Incidence of interval colorectal cancer among inflammatory bowel disease patients undergoing regular colonoscopic surveillance. Clin Gastroenterol Hepatol 2015;13:1656-1661.

9. Annese V, Daperno M, Rutter MD, et al. European evidence based consensus for endoscopy in inflammatory bowel disease. J Crohns Colitis 2013;7:982-1018.

10. Laine L, Kaltenbach T, Barkun A, McQuaid KR, Subramanian V, Soetikno R. SCENIC international consensus statement on surveillance and management of dysplasia in inflammatory bowel disease. Gastroenterology 2015;148:639-651.e28.

11. American Society for Gastrointestinal Endoscopy Standards of Practice Committee, Shergill AK, Lightdale JR, et al. The role of endoscopy in inflammatory bowel disease. Gastrointest Endosc 2015;81:1101-1121.e1e13.

12. Soetikno R, Subramanian V, Kaltenbach T, et al. The detection of nonpolypoid (flat and depressed) colorectal neoplasms in patients with inflammatory bowel disease. Gastroenterology 2013;144:1349-1352, 1352. e1-e6.

13. Blackstone MO, Riddell RH, Rogers BH, Levin B. Dysplasia-associated lesion or mass (DALM) detected by colonoscopy in long-standing ulcerative colitis: an indication for colectomy. Gastroenterology 1981;80:366374.

14. Itzkowitz SH, Harpaz N. Diagnosis and management of dysplasia in patients with inflammatory bowel diseases. Gastroenterology 2004;126:1634-1648.

15. Lee SH, Shin SJ, Park DI, et al. Korean guideline for colonoscopic polypectomy. Clin Endosc 2012;45:11-24.

16. Kudo S, Rubio CA, Teixeira CR, Kashida H, Kogure E. Pit pattern in colorectal neoplasia: endoscopic magnifying view. Endoscopy 2001;33:367373.

17. Kudo S, Lambert R, Allen JI, et al. Nonpolypoid neoplastic lesions of the colorectal mucosa. Gastrointest Endosc 2008;68(4 Suppl):S3-S47.

18. Ikematsu H, Matsuda T, Emura F, et al. Efficacy of capillary pattern type IIIA/IIIB by magnifying narrow band imaging for estimating depth of invasion of early colorectal neoplasms. BMC Gastroenterol 2010;10:33.

19. Sumimoto K, Tanaka S, Shigita K, et al. Diagnostic performance of Japan NBI Expert Team classification for differentiation among noninvasive, superficially invasive, and deeply invasive colorectal neoplasia. Gastrointest Endosc 2017;86:700-709.

20. Backes Y, Moss A, Reitsma JB, Siersema PD, Moons LM. Narrow band imaging, magnifying chromoendoscopy, and gross morphological features for the optical diagnosis of $\mathrm{T} 1$ colorectal cancer and deep submucosal invasion: a systematic review and meta-analysis. Am J Gastroenterol 2017;112:54-64. 
21. Wada Y, Kashida H, Kudo SE, Misawa M, Ikehara N, Hamatani S. Diagnostic accuracy of pit pattern and vascular pattern analyses in colorectal lesions. Dig Endosc 2010;22:192-199.

22. Li M, Ali SM, Umm-a-OmarahGilani S, Liu J, Li YQ, Zuo XL. Kudo’s pit pattern classification for colorectal neoplasms: a meta-analysis. World J Gastroenterol 2014;20:12649-12656.

23. Hata K, Watanabe T, Motoi T, Nagawa H. Pitfalls of pit pattern diagnosis in ulcerative colitis-associated dysplasia. Gastroenterology 2004;126:374376.

24. Bisschops R, Bessissow T, Dekker E, et al. Pit pattern analysis with high-definition chromoendoscopy and narrow-band imaging for optical diagnosis of dysplasia in patients with ulcerative colitis. Gastrointest Endosc 2017;86:1100-1106.e1.

25. Carballal S, Maisterra S, López-Serrano A, et al. Real-life chromoendoscopy for neoplasia detection and characterisation in long-standing IBD. Gut 2018;67:70-78.

26. Kiesslich R, Fritsch J, Holtmann M, et al. Methylene blue-aided chromoendoscopy for the detection of intraepithelial neoplasia and colon cancer in ulcerative colitis. Gastroenterology 2003;124:880-888.

27. Kinoshita S, Uraoka T, Nishizawa T, et al. The role of colorectal endoscopic submucosal dissection in patients with ulcerative colitis. Gastrointest Endosc 2018;87:1079-1084.

28. Uno Y, Munakata A. The non-lifting sign of invasive colon cancer. Gastrointest Endosc 1994;40:485-489.

29. Saito Y, Otake Y, Sakamoto T, et al. Indications for and technical aspects of colorectal endoscopic submucosal dissection. Gut Liver 2013;7:263269.

30. Yang DH, Jeong GH, Song Y, et al. The feasibility of performing colorectal endoscopic submucosal dissection without previous experience in performing gastric endoscopic submucosal dissection. Dig Dis Sci 2015;60:3431-3441.

31. Toyonaga T, Nishino E, Man IM, East JE, Azuma T. Principles of quality controlled endoscopic submucosal dissection with appropriate dissection level and high quality resected specimen. Clin Endosc 2012;45:362374

32. Iacopini F, Saito Y, Yamada M, et al. Curative endoscopic submucosal dissection of large nonpolypoid superficial neoplasms in ulcerative colitis (with videos). Gastrointest Endosc 2015;82:734-738.

33. Yang DH, Kim J, Song EM, et al. Outcomes of ulcerative colitis-associated dysplasia patients referred for potential endoscopic submucosal dissection. J Gastroenterol Hepatol 2019 Feb 6 [Epub]. https://doi. org/10.1111/jgh.14623.

34. Fujishiro M, Yahagi N, Kashimura K, et al. Comparison of various submucosal injection solutions for maintaining mucosal elevation during endoscopic mucosal resection. Endoscopy 2004;36:579-583.

35. Vieth M, Neumann H. Current issues in inflammatory bowel disease neoplasia. Histopathology 2015;66:37-48.

36. Langner C, Magro F, Driessen A, et al. The histopathological approach to inflammatory bowel disease: a practice guide. Virchows Arch 2014;464:511-527.

37. Allende D, Elmessiry M, Hao W, et al. Inter-observer and intra-observer variability in the diagnosis of dysplasia in patients with inflammatory bowel disease: correlation of pathological and endoscopic findings. Col- orectal Dis 2014;16:710-718; discussion 718.

38. Eaden J, Abrams K, McKay H, Denley H, Mayberry J. Inter-observer variation between general and specialist gastrointestinal pathologists when grading dysplasia in ulcerative colitis. J Pathol 2001;194:152-157.

39. Odze RD, Goldblum J, Noffsinger A, Alsaigh N, Rybicki LA, Fogt F. Interobserver variability in the diagnosis of ulcerative colitis-associated dysplasia by telepathology. Mod Pathol 2002;15:379-386.

40. Suzuki N, Toyonaga T, East JE. Endoscopic submucosal dissection of colitis-related dysplasia. Endoscopy 2017;49:1237-1242.

41. Ten Hove JR, Mooiweer E, Dekker E, et al. Low rate of dysplasia detection in mucosa surrounding dysplastic lesions in patients undergoing surveillance for inflammatory bowel diseases. Clin Gastroenterol Hepatol 2017; 15:222-228.e2.

42. Krugliak Cleveland N, Huo D, Sadiq F, et al. Assessment of peri-polyp biopsy specimens of flat mucosa in patients with inflammatory bowel disease. Gastrointest Endosc 2018;87:1304-1309.

43. Lahiff C, Mun Wang L, Travis SPL, East JE. Diagnostic yield of dysplasia in polyp-adjacent biopsies for patients with inflammatory bowel disease: a cross-sectional study. J Crohns Colitis 2018;12:670-676.

44. Patel N, Patel K, Ashrafian H, Athanasiou T, Darzi A, Teare J. Colorectal endoscopic submucosal dissection: systematic review of mid-term clinical outcomes. Dig Endosc 2016;28:405-416.

45. Akintoye E, Kumar N, Aihara H, Nas H, Thompson CC. Colorectal endoscopic submucosal dissection: a systematic review and meta-analysis. Endosc Int Open 2016;4:E1030-E1044.

46. Fuccio L, Hassan C, Ponchon T, et al. Clinical outcomes after endoscopic submucosal dissection for colorectal neoplasia: a systematic review and meta-analysis. Gastrointest Endosc 2017;86:74-86.e17.

47. Baars JE, Siegel CA, van't Spijker A, Markus T, Kuipers EJ, van der Woude CJ. Inflammatory bowel disease-patients are insufficiently educated about the basic characteristics of their disease and the associated risk of colorectal cancer. Dig Liver Dis 2010;42:777-784.

48. Siegel CA, Schwartz LM, Woloshin S, et al. When should ulcerative colitis patients undergo colectomy for dysplasia? Mismatch between patient preferences and physician recommendations. Inflamm Bowel Dis 2010;16:1658-1662.

49. Lopez A, Collet-Fenetrier B, Belle A, Peyrin-Biroulet L. Patients' knowledge and fear of colorectal cancer risk in inflammatory bowel disease. J Dig Dis 2016;17:383-391.

50. Hahnloser D, Pemberton JH, Wolff BG, Larson DR, Crownhart BS, Dozois RR. Results at up to 20 years after ileal pouch-anal anastomosis for chronic ulcerative colitis. Br J Surg 2007;94:333-340.

51. Heikens JT, de Vries J, Goos MR, Oostvogel HJ, Gooszen HG, van Laarhoven CJ. Quality of life and health status before and after ileal pouchanal anastomosis for ulcerative colitis. Br J Surg 2012;99:263-269.

52. Yoon YS, Cho YB, Park KJ, et al. Surgical outcomes of Korean ulcerative colitis patients with and without colitis-associated cancer. World J Gastroenterol 2015;21:3547-3553.

53. Fazio VW, Kiran RP, Remzi FH, et al. Ileal pouch anal anastomosis: analysis of outcome and quality of life in 3707 patients. Ann Surg 2013;257:679-685.

54. Beaugerie L, Itzkowitz SH. Cancers complicating inflammatory bowel disease. N Engl J Med 2015;372:1441-1452. 